\title{
Paralympics - Barcelona 1992
}

\author{
John Reynolds MB BS, MRCP(UK), Angela Stirk Grad Dip Phys Ed MCSP, \\ Austin Thomas RGN RCNT RNT, BEd and Fiona Geary Grad Dip Phys MCSP \\ British Paralympic Association, Croydon, Surrey, UK
}

The British Team at the 9th Paralympic Games in September 1992 in Barcelona comprised 151 men and 54 women athletes in a total of 15 sports. They were supported by a staff of 86 including a 12-strong medical team. The athletes were selected from the National Championships of the five disability organizations: British Wheelchair Sports Federation; British Blind Sport; Cerebral Palsy Sport; British Amputee Sports Association; and the British Les Autres Sports Association. This article outlines the organization and experience of the medical support team. The injury/illness profile was similar to those in able bodied sport. The team went on to achieve $\mathbf{4 0}$ gold, 47 silver and $\mathbf{4 1}$ bronze medals, maintaining third place on the medal table as achieved in Seoul in 1988.

Keywords: Paralympic, games, disabled sport

The Paralympic Games took place in Barcelona in the first two weeks of September 1992. The games are the most important sporting event in the world for the physically and sensorily disabled athlete. The élite of the world's disabled athletes take part in competition at the highest level.

A total of 15 sports was staged, 12 of which appear in the Olympic Games programme, though slight modifications are made to their rules to adapt them to disabled sport. Three sports, including boccia, goalball and seven-a-side football are specifically for disabled athletes.

The UK team at the 9th Paralympic Games in Barcelona 1992 comprised 151 men and 54 women athletes, competing in a total of 15 sports. The team was supported by a staff of 86 comprising management, coaches, escorts, guide runners and a 12strong medical team.

\section{Medical team composition}

The medical team included two physicians (an orthopaedic physician and a general practitioner), seven physiotherapists, two nurses with special expertise in spinal injury, and one prosthetist. The team was selected by the chief medical officer. Previous experience in sport and disability were prerequisites to selection.

Address for correspondence: Dr John Reynolds, Room G13A, Delta Point, 35 Wellesley Road, Croydon CR9 2YZ, UK

(C) 1994 Butterworth-Heinemann Ltd 0306-3674/94/010014-04

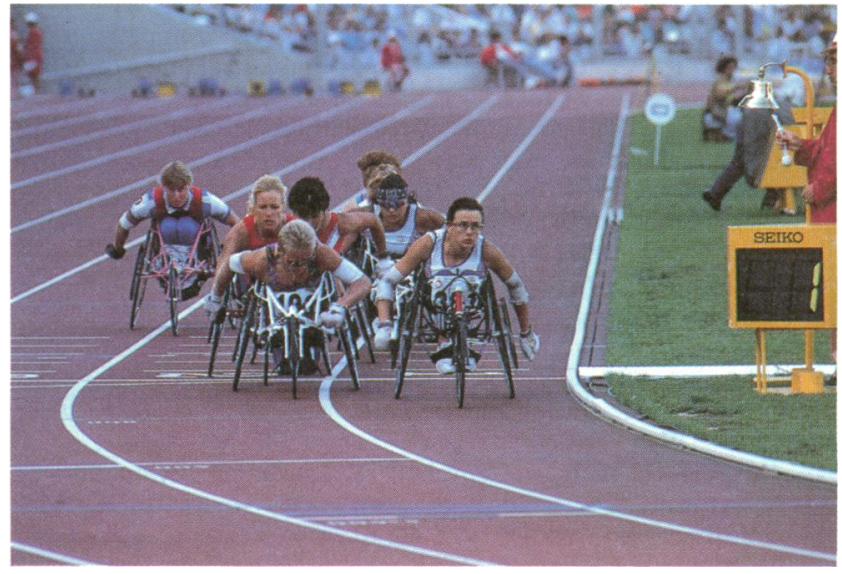

Figure 1. Britain's Tanni Gray on her way to a gold medal

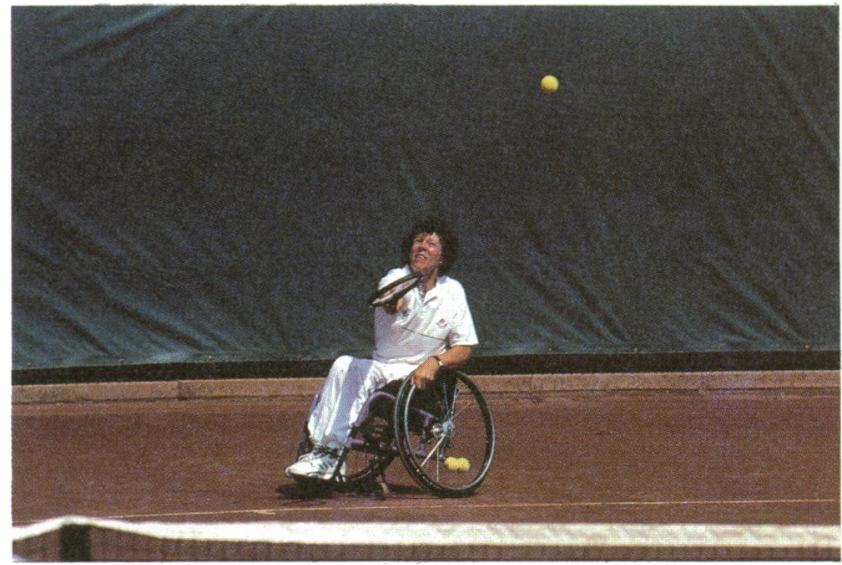

Figure 2. Wheelchair tennis

The British team was accommodated in a single block within the Olympic village. The medical suite was situated on the ground floor adjacent to the UK administrative headquarters, thus providing easy access for the team and management. The clinic comprised a separate consulting room, a nursing area and a large physiotherapy treatment area with four cubicles fully equipped with treatment couches, desks, storage and ice maker. Toilet and washing facilities were also included. All the facilities were provided to the UK delegation by the Spanish hosts. 


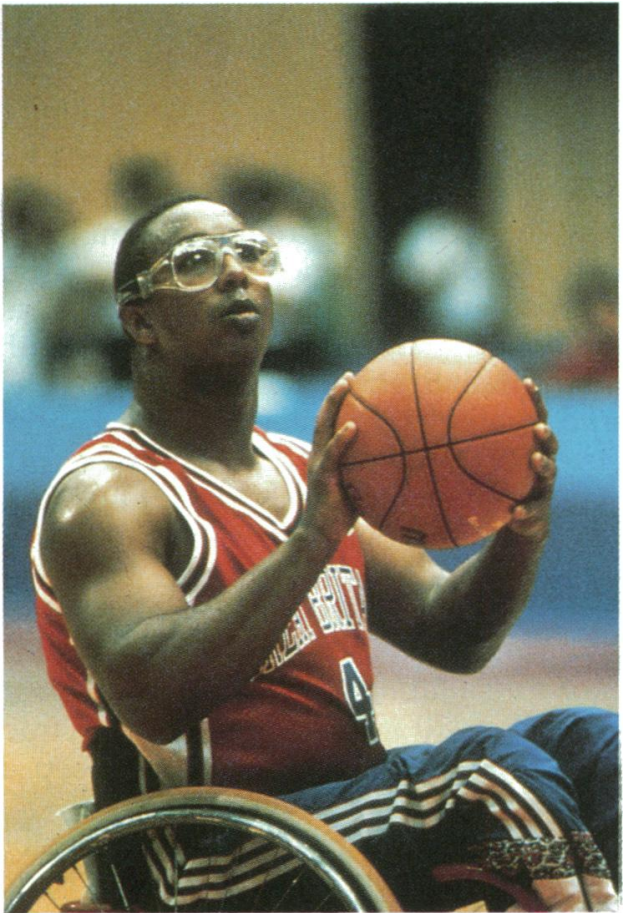

Figure 3. Wheelchair basketball 'free throw'

\section{Physiotherapy equipment list}

The following equipment was kindly loaned to the British Paralympic Association for the duration of the games: Enraf Nonius Sonapuls 464; Enraf Nonius Endolaser 476; Enraf Nonius Sonapuls 590; Enraf Nonius Endomed 582 Interferential; Omega 3ML Laser (Omega Universal Technologies, London, UK); two Likon electrostimulators (Lederle, Gosport, UK);

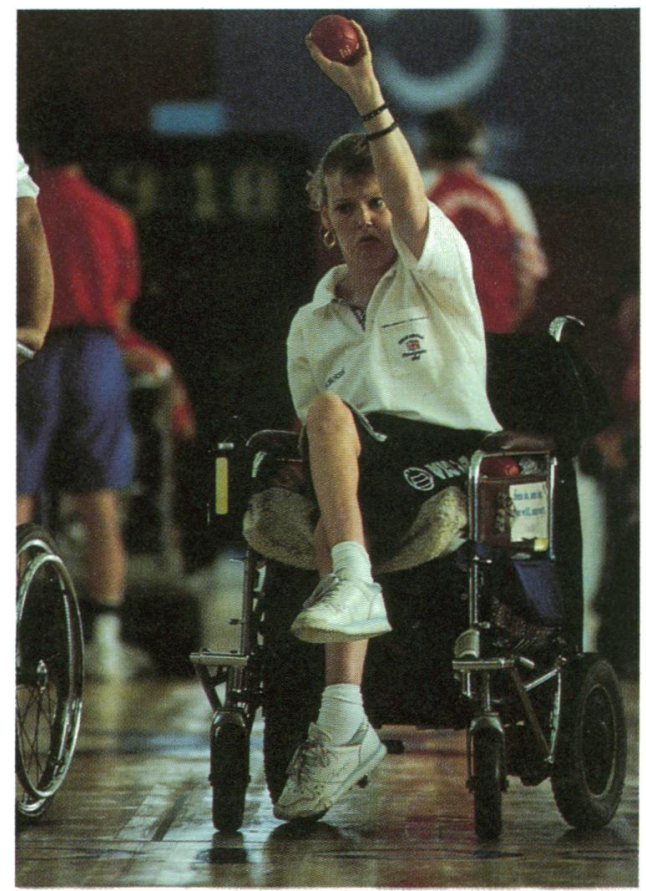

Figure 4. Boccia - a game for the severely disabled cerebral palsy athletes, akin to 'boules'

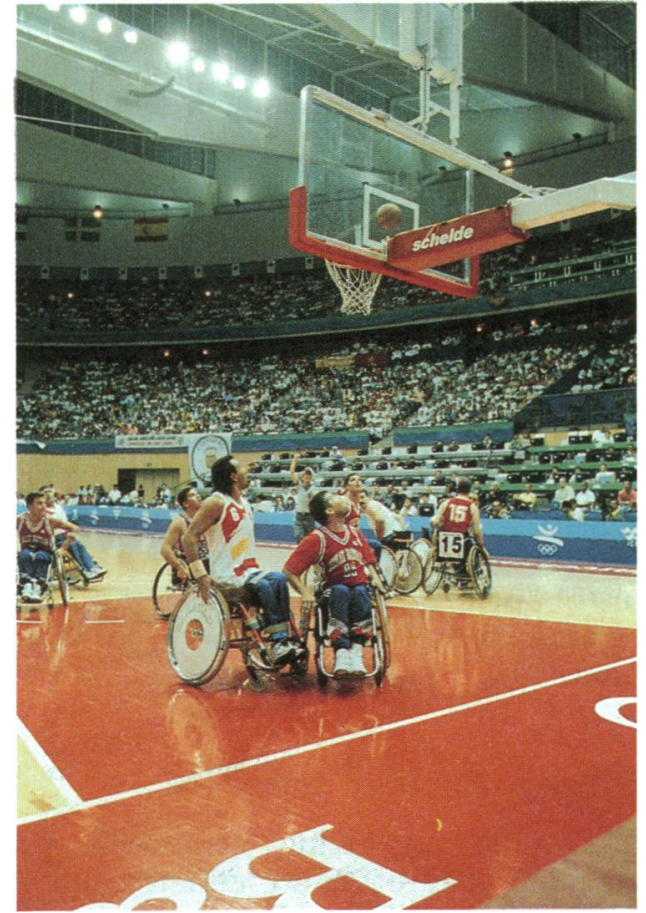

Figure 5. Wheelchair basketball at Barcelona Stadium

and six TENS of various makes (Raymar, Henley, UK).

A large supply of consumable items and full range of medication, most of which was donated, allowed the physicians to treat the vast majority of problems without use of the local pharmacy. We are most grateful to the British Olympic Medical Centre at Northwick Park Hospital and Southport and Formby Hospital Suppliers for supplying these stocks.

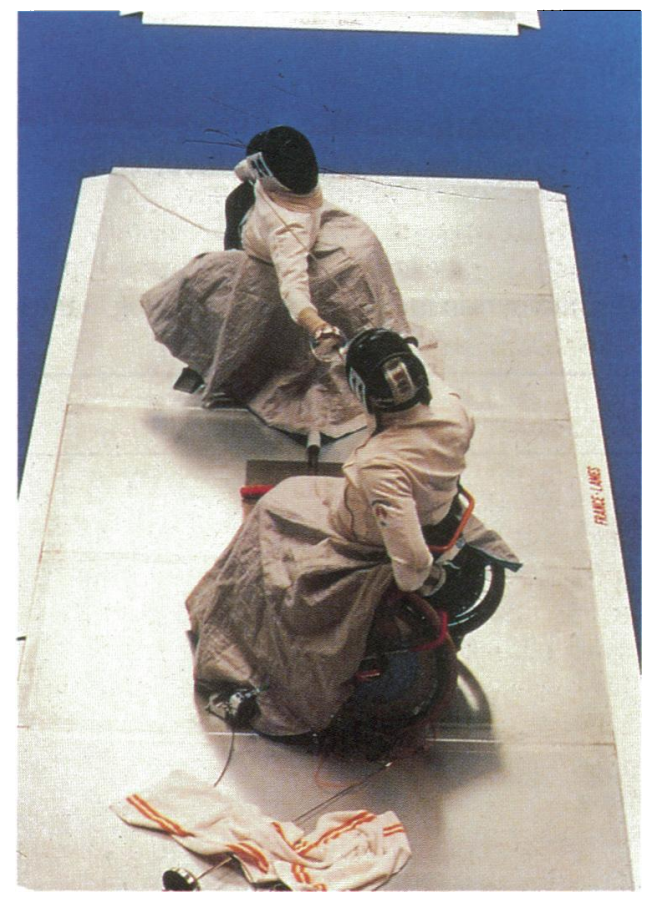

Figure 6. Wheelchair fencing 


\section{Organization of the medical team}

Before the games it was decided to run a core medical group rather than individual squads taking their own medical support. The physiotherapy rota was organized so that at any one time there were at least two therapists in the clinic between 07.30 hours and 22.00 hours. The remaining therapists attended the main sports venues to provide treatment/massage for the athletes before and after competition. The doctors provided morning and evening surgeries and also visited the competition venues whenever possible. A 24-h on-call system was organized with the help of a mobile telephone and paging system. The two nursing staff organized themselves to provide 24-h cover and constant presence within the clinic during the hours of opening. The medical service was begun 4 days before the competition and closed the day before departure.

\section{Host country back up facilities}

The Paralympic organizing committee provided excellent medical care for the athletes and support staff. Within the village, a large polyclinic offered 24-h primary/emergency care, a full range of specialist outpatient services, a pharmacy and a large and well equipped rehabilitation department. At each of the sports venues they provided medical and first aid teams for the entire duration of competition. First class hospital facilities were available if problems exceeded the scope of individual team medical facilities and the polyclinic. All medical facilities were provided free of charge.

\section{The sports}

The squad breakdown is shown in Table 1.

\section{Statistics}

Out of a total team of 291 competitors and staff, 201 team members attended the medical centre at some

Table 1. The numbers in the UK team participating in the different sports

\begin{tabular}{lr}
\hline Sport & No. \\
\hline Athletics & 60 \\
Swimming & 43 \\
Archery & 10 \\
Basketball & 12 \\
Boccia & 4 \\
Cycling & 5 \\
Tennis & 4 \\
Fencing & 7 \\
Judo & 5 \\
Powerlifting & 4 \\
Weightlifting & 4 \\
Shooting & 11 \\
Soccer & 11 \\
Table tennis & 13 \\
Volleyball & 10 \\
\hline
\end{tabular}

time during the games: 82 were seen by doctors; 77 were seen by nurses; and 146 were seen by physiotherapists.

Serious illness and injury was fortunately rare. No admission to hospital was necessary. One athlete was seen by a specialist for acute renal colic but settled quickly without further problems. Another athlete with Factor VIII deficiency suffered a significant haemarthrosis and soft tissue bleed but was managed successfully within the UK medical centre with Factor VIII and immobilization. On return to the UK it transpired that a staff member had continued to experience diarrhoeal illness, and subsequent investigation confirmed amoebiasis. In view of the high levels of hygiene control within the village it is assumed that the infection was contracted elsewhere.

The commonest problems encountered by the doctors and nurses, given as percentages of the total number of consultations, were: mosquito bites $(11 \%)$; fungal infection $(10 \%)$; upper respiratory tract infections $(9 \%)$; diarrhoea/vomiting $(8 \%)$; sleep disturbance $(5 \%)$; and pressure sores $(4 \%)$.

The physiotherapy workload was predictably high, both for active treatment and massage. Injury rates by body region are shown in Table 2 .

Table 3 indicates the percentage of each squad suffering injury before or during training/ competition.

Table 2. Percentage injury rates by body region

\begin{tabular}{lr}
\hline Body region & $\%$ \\
\hline Cervical spine & 17 \\
Shoulder & 9 \\
Knee & 5 \\
Fingers & 3 \\
Ribs & 3 \\
Lumbar spine & 11 \\
Hand & 6 \\
Stump sores & 5 \\
Thumb & 3 \\
Elbows & 3 \\
\hline
\end{tabular}

Table 3. Injuries to all squads during training and competition

\begin{tabular}{lr}
\hline Sport & \% injured \\
\hline Track and field & 80 \\
Swimming & 69 \\
Cycling & 17 \\
Volleyball & 90 \\
Judo & 80 \\
Tennis & 75 \\
Weightlifting & 50 \\
Basketball & 79 \\
Shooting & 55 \\
Football & 73 \\
Archery & 60 \\
Fencing & 71 \\
Table tennis & 69 \\
Power lifting & 75 \\
Support staff & 42 \\
\hline
\end{tabular}




\section{Discussion}

The 9th Paralympic Games were undoubtedly a great success. The organization was superb and the competition standards higher than ever before. The athletes are the élite of their sport and train to exceptionally high levels of fitness and skill. Consequent upon this is a significantly high level of training and competition injury. The relationship between the medical staff and the athletes was extremely good. The balance in the medical team proved to be about right and we could not recommend higher levels of medical staffing for a team of this size. The only significant change for the future may be the inclusion of one or two massage therapists to relieve some physiotherapy time.

To date many of our paralympic athletes have not developed close relationships with sports injury 'experts'. There is not yet any provision made for them to receive private physiotherapy care should they become injured. Before the games all team members were required to declare any medical problems. Not unsurprisingly few injuries were declared. On arrival in the paralympic village however, quite large numbers of athletes and support staff were presenting almost immediately for treatment to pre-existing injuries. Fortunately most were fairly minor. There would appear to be a need, however, to improve our pre-event screening procedures, and to provide much better access to specialist help should an élite athlete become injured.

Traditionally, disabled athletes have often competed in a number of events during the course of major games. As standards have risen this has become increasingly demanding on the athletes. There were a number of occasions in Barcelona when our competitors were overstretched by trying to compete in too many events. Some resulted in significant injury and reduced performance ability. One of our recommendations to team management is to look closely at this point to try to prevent problems at future competitions.
It may be of interest to those readers who have not worked with disabled athletes to see that the medical problems encountered on a trip such as this are essentially the same as in able bodied sport. Due to the presence of a high proportion of wheelchair athletes, there do tend to be more upper body problems compared with the normal preponderance of lower limb injury. Few problems occur that are specific to the competitors' disabilities. Therefore, in medical team selection, we feel that emphasis should be placed on orthopaedic medical skills and sports injury experience, rather than neurological training. There is of course a place for the neurophysiotherapist for those athletes with severe spasticity. In the modern paralympic team however, these comprise but a few.

On a note of self criticism, when we came to look at the treatment statistics for these games it rapidly became apparent that our record keeping had been far from ideal. Many follow-up physiotherapy sessions had not been recorded and massage before and after events was hardly ever noted. The figures we have given therefore, are a significant underrepresentation. We estimate that an adjustment of $15 \%$ would give a more realistic picture of total treatment sessions. A lack of recorded soft tissue diagnosis has also made an analysis of the physiotherapy experience difficult. In the light of these problems the British Paralympic Association medical commission is in the process of designing an appropriate treatment record card to encourage more accurate documentation in the future.

In conclusion we can only say that it was a great privilege to be part of the UK team at the 9th Paralympic Games. Disabled sport has most certainly come of age and we are fortunate to have a strong squad of fine athletes in the UK. We would recommend that more medical and paramedical personnel involve themselves in the support of this important group of athletes.

volleyball players $M$ Holzgraefe, B Kukowski, S Eggert

Radiographic changes in the hands of rockclimbers $S R$ Bollen, $V$ Wright 